\title{
Echocardiographic Findings in Patients with Mild to Moderate Chronic Kidney Disease without Symptomatic Heart Failure: A Population-Based Study
}

\author{
Liana Xhakollari a, b Margret Leosdottir ${ }^{b, c}$ Martin Magnusson ${ }^{b, c, f}$ \\ Martin J. Holzmann ${ }^{d, e}$ Peter M. Nilsson ${ }^{b}$ Anders Christensson ${ }^{a, b}$ \\ aDepartment of Nephrology, Skåne University Hospital, Malmö, Sweden; ${ }^{\text {b}}$ Department \\ of Clinical Sciences Malmö, Lund University, Malmö, Sweden; ' Department of Cardiology, \\ Skåne University Hospital, Malmö, Sweden; ${ }^{\mathrm{d}}$ Department of Medicine, Karolinska Institutet, \\ Stockholm, Sweden; ${ }^{e}$ Functional Area of Emergency Medicine, Karolinska University \\ Hospital, Stockholm, Sweden; fWallenberg Center for Molecular Medicine, Lund University, \\ Lund, Sweden
}

\section{Keywords}

Cardiorenal syndrome · Diastolic dysfunction · Echocardiography · Glomerular filtration rate $\cdot$ Tissue Doppler imaging

\begin{abstract}
Background: Renal dysfunction is an established risk factor for cardiovascular disease, but early disease states in both organs are poorly studied. Objective: This cross-sectional population-based study aims to investigate if there is an early association between kidney function and echocardiographic markers of cardiac structure and diastolic function. Methods: The study population consisted of 1,504 individuals with no prior history of congestive heart failure or asymptomatic left ventricular ejection fraction $\leq 40 \%$ and an estimated glomerular filtration rate (eGFR) based on cystatin $\mathrm{C}>15 \mathrm{~mL} / \mathrm{min} / 1.73 \mathrm{~m}^{2}$. The participants were categorized according to eGFR $\geq 90,75-89,60-74,45-59,30-44$, and $15-29 \mathrm{~mL} / \mathrm{min} / 1.73 \mathrm{~m}^{2}$. We evaluated associations between eGFR categories and echocardiographic findings specific to cardiac structure and diastolic function. Results: Associations between eGFR categories and echocardiographic findings were found for left atrium area/body surface area $(p=0.013)$ indicating structural changes, and peak early mitral valve velocity $(A ; p=0.003)$, peak late atrial mitral valve velocity/peak systolic myocardial velocity at mitral annulus in the lateral wall (E/Élat; $p=0.002)$, É mean of lateral and septal wall/Á mean of lateral and septal wall (mean É/Á; $p=0.027$ ) indicating diastolic dysfunction. Associations between E/Élat and mean É/Á and eGFR categories were already present in individuals with eGFR $45-60 \mathrm{~mL} / \mathrm{min} / 1.73 \mathrm{~m}^{2}$. In
\end{abstract}


sex-specific analysis these associations were only significant among men. Conclusion: A significant association between mild to moderate impairment of renal function and echocardiographic markers of cardiac structure and diastolic function was observed, supporting the hypothesis that interaction between the kidney and heart exists even in the early stages of renal impairment.

(C) 2019 S. Karger AG, Basel

\section{Introduction}

Chronic kidney disease (CKD) is an established independent risk factor for cardiovascular disease (CVD) [1]. It is known that heart disease can affect renal function leading to CKD [2]. This pathophysiological association between heart and kidney diseases is referred to as a form of cardiorenal syndrome $[2,3]$ and is especially common among patients with congestive heart failure (CHF) [4].

Mortality and morbidity are increased in patients with concomitant kidney and heart dysfunction when compared to patients with only one of the organs affected [5]. The relationship between CKD and CHF is well described not only in patients with severe renal dysfunction (CKD stage 4-5) [1], but also in patients with milder renal dysfunction [6].

Cystatin $\mathrm{C}$ (CysC) has emerged as a more accurate measurement of renal function than creatinine, especially in patients with extremes of body size since it is not dependent on muscle mass [7]. Also, in terms of predicting risk for heart failure [8] CysC has appeared superior to creatinine.

Echocardiography with tissue Doppler imaging (TDI) is a method that provides a precise measure of left ventricular (LV) wall motion and thus an attractive option to quantify global and regional LV function. This method demonstrates high sensitivity to detect early signs of both diastolic and mild systolic LV dysfunction. Assessment of the mitral annular velocity allows the determination of regional wall mechanics and ejection fraction. In patients with CKD, myocardial tissue abnormalities can influence LV relaxation and compliance, causing systolic and diastolic dysfunction (DD) [9].

Only a few previous community-based studies report on the association between renal function and echocardiographic-based LV function [10]. In recent years studies have shown that even a minor reduction of the glomerular filtration rate (GFR) can be associated with changes in cardiac structure $[11,12]$. However, there is little knowledge about the association between early renal impairment and echocardiographic functional parameters indicating DD in community-based cohorts. The two studies which have attempted to assess this association have had conflicting results $[10,12]$. In light of this gap in the evidence we performed the current study to evaluate if the association between mild to moderate renal dysfunction and cardiac structure and function indicating DD exists in individuals without CHF or asymptomatic reduced $\mathrm{LV}$ function.

\section{Materials and Methods}

Subjects

The Malmö Prevention Project (MPP), based in Malmö, Sweden, was a population-based cross-sectional program that invited participants from selected age groups living in Malmö [13]. Individuals were enrolled from 1974 to 1992 and participation across each age group was 71\% on average. A detailed description of the recruitment and screening protocol has been published previously [14].

In the MPP Re-Examination Study (MPP-RES), conducted between 2002 and 2006, approximately 25,000 individuals from the MPP who were still alive and living in Malmö [15] were invited to participate in a 
Fig. 1. Schematic description of the selection of the study population. CHF, congestive heart failure; eGFR, estimated glomerular filtration rate; CysC, cystatin C; LVEF, left ventricular ejection fraction.

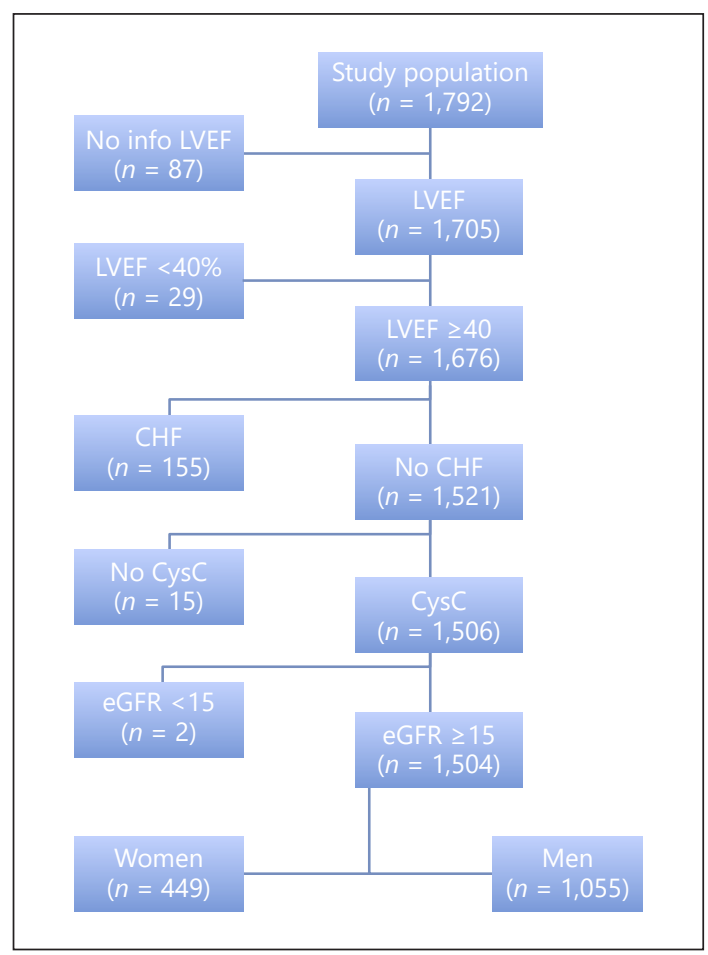

re-screening project. A total of 18,238 (73\%) accepted the invitation. Blood samples were obtained after overnight fasting. Blood pressure ( $\mathrm{mm} \mathrm{Hg}$ ) and pulse rate (beats per minute), height ( $\mathrm{cm}$ ) and weight $(\mathrm{kg})$, and hip and waist circumferences $(\mathrm{cm})$ were measured. The individuals answered a self-administered questionnaire about alcohol consumption, smoking and physical activity, short medical history, medications, and their general state of health. Additionally, a subsample of 1,792 individuals with a mean age of $67 \pm 6$ years was randomly selected from groups defined by glucose metabolism: normal fasting glucose $(\leq 6.0 \mathrm{mmol} / \mathrm{L})$, impaired fasting glucose, new-onset type 2 diabetes mellitus (DM), and prevalent DM both types 1 and 2. An oversampling in groups of individuals with disturbances of glucose metabolism was done to ensure sufficient numbers in each group [16]. All 1,792 individuals were examined with echocardiography and electrocardiogram.

In this study we excluded individuals with a history of CHF (irrespective of LV ejection fraction; LVEF), based on a hospital registry diagnosis (ICD 10 I50) of CHF. Individuals with a reduced LVEF $(<40 \%)$ were also excluded [17]. In addition, individuals with LVEF between 41 and 55\% were excluded if they reported being prescribed 2 or more drugs used for the treatment of heart failure (angiotensin-converting enzyme inhibitors, angiotensin receptor blockers, diuretics, or beta-blockers). Additionally, those with missing information on LVEF $(n=87)$ and those without a measurement of CysC $(n=15)$ were excluded, leaving 1,504 individuals for this study (Fig. 1).

\section{Echocardiography}

Echocardiography was conducted with a 3V2c transducer or an S3 transducer. Parasternal long- and short-axis and apical two- and four-chamber views were used to evaluate LVEF and cardiac dimensions. LVEF was visually quantified. LV mass calculations were based on end-diastolic measurements in the parasternal long-axis view at the level of the mitral tips consistent with M-mode criteria, and subsequently indexed for body surface area (BSA) [15].

Transmitral pulsed Doppler flow and TDI in the four-chamber view were used to measure LV diastolic function. Peak myocardial velocity of the basal LV wall in the early (É) and late (Á) diastole in the lateral (lat) and septal (sept) walls, and Doppler measurement of peak velocity of blood flow through the mitral valve in the early (E) and late (A) diastole were measured. A single cycle was used if the registrations were homogeneous; otherwise, a mean of 3-5 cycles was used. 
Xhakollari et al.: Echocardiographic Findings in Patients with Mild to Moderate Chronic

Laboratory Tests

Plasma CysC was measured by a fully automated particle-enhanced immunoturbidimetric assay [7]. The reagents were obtained from DAKO (Dako A/S, Glostrup, Denmark) and the determination was performed on the Hitachi Modular P analysis system. The total analytical imprecision was $2.1 \%$ (using a control sample at a concentration of $1.0 \mathrm{mg} / \mathrm{L}$ ) and $1.7 \%$ (at a level of $4.0 \mathrm{mg} / \mathrm{L}$ ). The reference range was $0.55-1.15 \mathrm{mg} / \mathrm{L}$ (1-50 years) and $0.63-1.44 \mathrm{mg} / \mathrm{L}$ ( $>50$ years) [18]. The analyses were performed before the introduction of the international reference calibrator preparation ERM-DA 471/IFCC. High-density lipoprotein, fasting blood glucose, and hemoglobin were analyzed with standard procedures at the Department of Clinical Chemistry at Skåne University Hospital, Malmö, Sweden.

Other Definitions

Blood pressure and pulse rate were measured in the supine position after $10 \mathrm{~min}$ of rest, with two separated measures performed [15]. Hypertension was defined as a history of treated hypertension and/or a mean blood pressure at baseline $\geq 140$ or $\geq 90 \mathrm{~mm} \mathrm{Hg}$. Weight and height were measured in light indoor clothing without shoes.

\section{Estimated GFR Formula}

We estimated GFR (eGFR) from CysC with the CKD-Epidemiology Collaboration (CKD-EPI) CysC equation [19]: $133 \times \min .(\mathrm{Cys} / 0.8,1)^{-0.499} \times \max .(\mathrm{CysC} / 0.8,1)^{-0.328} \times 0.996^{\text {Age }} \times 0.932$ (if female), where min. indicates the minimum of CysC/0.8 or 1 , and max the maximum of CysC/0.8 or 1 .

We used the KDIGO classification of CKD stages [20]. CKD stage 1 and 2 were classified only according to eGFR levels. We used the following definitions of CKD stages: 1, normal GFR $>90 \mathrm{~mL} / \mathrm{min} / 1.73 \mathrm{~m}^{2} ; 2$, mildly decreased GFR $60-89 \mathrm{~mL} / \mathrm{min} / 1.73 \mathrm{~m}^{2}$; 3a, mildly to moderately decreased GFR 45-59 mL/min/1.73 $\mathrm{m}^{2}$; 3b, moderately to severely decreased GFR 30-44 mL/min/1.73 $\mathrm{m}^{2} ; 4$, severely decreased GFR 15-29 $\mathrm{mL} / \mathrm{min} / 1.73 \mathrm{~m}^{2}$, and 5 , renal failure $<15 \mathrm{~mL} / \mathrm{min} / 1.73 \mathrm{~m}^{2}$ [20]. The vast majority of individuals $(61.1 \%$, $n=919$ ) belonged to CKD 2. Therefore, we further divided CKD 2 into 75-89 and 60-74 $\mathrm{mL} / \mathrm{min} /$ $1.73 \mathrm{~m}^{2}$ (Table 1).

\section{Statistical Analyses}

First associations between eGFR categories and echocardiographic indices were studied using a univariate general linear model analysis (UNIANOVA) adjusting for age and sex only. All echocardiographic variables which were then associated with eGFR categories with a $p$ value $<0.1$ in the first analysis were further tested in a multivariable analysis adjusting for renin-angiotensin-aldosterone system (RAAS) blockade, DM, smoking, and hypertension. All of the variables adjusted for were binary, except age.

We then compared the mean effects for eGFR categories to evaluate which categories differed from each other. A $p$ value $<0.05$ was considered statistically significant. These analyses were done for $45-60$ versus $>$ $90 \mathrm{~mL} / \mathrm{min} / 1.73 \mathrm{~m}^{2}$ and $45-60$ versus $>60 \mathrm{~mL} / \mathrm{min} / 1.73 \mathrm{~m}^{2}$, as well as for 30-60 versus $>90 \mathrm{~mL} / \mathrm{min} / 1.73$ $\mathrm{m}^{2}$ and $30-60$ versus $>60 \mathrm{~mL} / \mathrm{min} / 1.73 \mathrm{~m}^{2}$.

In a subgroup analysis of individuals with eGFR $>60 \mathrm{~mL} / \mathrm{min} / 1.73 \mathrm{~m}^{2}$ we studied the associations between eGFR as a continuous variable and echocardiographic indices. All calculations were performed first for the whole cohort and then stratified by gender. All statistical analyses were performed using SPSS (version 24.0; IBM Corp., Armonk, NY, USA).

\section{Results}

The selection of the study population is shown in Figure 1 and baseline characteristics are shown in Table 1. We also show the results of those 288 individuals who were excluded (as previously described). Unadjusted values for the different echocardiographic variables are shown in Table 2.

Associations between eGFR and Diastolic Function

In the first statistical analysis for the associations between eGFR categories and echocardiographic indices we used a univariate general linear model analysis (UNIANOVA) adjusting 
Xhakollari et al.: Echocardiographic Findings in Patients with Mild to Moderate Chronic Kidney Disease without Symptomatic Heart Failure: A Population-Based Study

Table 1. Baseline characteristics of the participants in the MPPRES

\begin{tabular}{|c|c|c|c|}
\hline & All & Included & Excluded \\
\hline Subjects, $n$ & 1,792 & 1,504 & 288 \\
\hline Age, years & $67.3 \pm 6$ & $66.9 \pm 6$ & $69.7 \pm 6$ \\
\hline Male gender & 70.6 & 70.1 & 73.3 \\
\hline Waist measurement, $\mathrm{cm}$ & $98.5 \pm 12$ & $97.8 \pm 12$ & $102.4 \pm 13$ \\
\hline BMI & $28.3 \pm 4$ & $28.1 \pm 4$ & $29.6 \pm 5$ \\
\hline \multicolumn{4}{|l|}{ Smoking } \\
\hline Now & 18.6 & 19.2 & 14.4 \\
\hline Before & 50.4 & 49.5 & 53.7 \\
\hline Never & 31.0 & 31.3 & 28.1 \\
\hline NT-proBNP, pmol/L & $28 \pm 63$ & $19.8 \pm 33$ & $72 \pm 134$ \\
\hline LVEF, \% & $60 \pm 8$ & $61 \pm 6$ & $54.1 \pm 14$ \\
\hline $\begin{array}{l}\text { CKD-EPI CysC, } \mathrm{mL} / \mathrm{min} / 1.73 \mathrm{~m}^{2} \\
\text { eGFR categories }\end{array}$ & $68.6 \pm 17$ & $69.7 \pm 16$ & $62 \pm 19$ \\
\hline$>90 \mathrm{~mL} / \mathrm{min} / 1.73 \mathrm{~m}^{2}$ & 10.4 & $11.1(167)$ & 7 \\
\hline $75-89.9 \mathrm{~mL} / \mathrm{min} / 1.73 \mathrm{~m}^{2}$ & 25.2 & $26.5(399)$ & 18.6 \\
\hline $60-74.9 \mathrm{~mL} / \mathrm{min} / 1.73 \mathrm{~m}^{2}$ & 33 & $34.6(520)$ & 25.3 \\
\hline $45-59.9 \mathrm{~mL} / \mathrm{min} / 1.73 \mathrm{~m}^{2}$ & 22.1 & $20.8(313)$ & 28.1 \\
\hline $30-44.9 \mathrm{~mL} / \mathrm{min} / 1.73 \mathrm{~m}^{2}$ & 6.9 & $6.4(97)$ & 9.5 \\
\hline $15-29.9 \mathrm{~mL} / \mathrm{min} / 1.73 \mathrm{~m}^{2}$ & 1.1 & $0.5(8)$ & 4.2 \\
\hline$<15 \mathrm{~mL} / \mathrm{min} / 1.73 \mathrm{~m}^{2}$ & 0.2 & & 1.1 \\
\hline HT & 62.9 & 64.6 & 54.4 \\
\hline RAAS & 23.5 & 20.5 & 40 \\
\hline DM & 35.5 & 34.3 & 42.1 \\
\hline
\end{tabular}

Data are presented as the mean \pm SD or $\%(n)$. NT-proBNP, N-terminal pro B-type natriuretic peptide; LVEF, left ventricular ejection fraction; CKD, chronic kidney disease; CKD-EPI CysC, CKD-Epidemiology Collaboration based on cystatin C; eGFR, estimated glomerular filtration rate; HT, hypertension; RAAS, reninangiotensin II-aldosterone system; DM, diabetes mellitus.

for age and sex only. Variables with an association with a $p$ value $<0.1$ were further analyzed in a multivariable analysis. These variables were: LVEF, A, E/Ésept, E/Élat, meanÉ/Á, meanE/É, LAarea (left atrium area), LASd (left atrium systolic diameter), LAsdm2 (left atrium dimension/BSA), and LAarea/BSA. Associations between eGFR categories and echocardiographic indices for diastolic function for the fully adjusted analyses are shown in Table 3 . The ratio between Doppler registration of peak velocity of blood flow through the mitral valve in the early diastole (E) and peak myocardial velocity of the basal lateral LV wall in the early diastole (Élat), e.g. E/Élat ( $p=0.002)$, and peak velocity through the mitral valve in the late diastole (A; $p=0.003$ ) were negatively associated with eGFR categories. The mean value of E/Élat and E/Ésept (mean E/É) was also significantly negatively associated with GFR categories ( $p=0.009$ ). The ratio between $E$ (mean of lat and sept) and the peak myocardial velocity of the basal LV wall in the late diastole (Á, mean of lat and sept), meanÉ/Á ( $p=0.027$ ), was positively associated with eGFR categories. All these results indicate that altered diastolic function was more common in participants with a lower eGFR.

Furthermore, in sex-specific analyses the associations between eGFR categories and echocardiographic variables were significant only among men for $\mathrm{A}(p<0.001)$, E/Élat ( $p=$ $0.039)$, and mean É/Á ( $p=0.019)$. There was a trend towards an association between mean $\mathrm{E} / \mathrm{E}$ and eGFR $(p=0.054)$. Among women there were no significant associations between eGFR categories and echocardiography indices (Table 3). 


\begin{tabular}{l|l}
\hline DOI: 10.1159/000499835 & $\begin{array}{l}\text { @ 2019 S. Karger AG, Basel } \\
\text { www.karger.com/crm }\end{array}$ \\
\hline
\end{tabular}

Xhakollari et al.: Echocardiographic Findings in Patients with Mild to Moderate Chronic Kidney Disease without Symptomatic Heart Failure: A Population-Based Study

Table 2. Unadjusted mean values $( \pm S D)$ for different echocardiographic variables for the whole cohort

\begin{tabular}{lcc}
\hline Variable & $n$ & Mean \pm SD \\
\hline LVEF, \% & 1,504 & $61.0 \pm 6.0$ \\
E, cm/s & 1,484 & $71.5 \pm 16.6$ \\
A,cm/s & 1,469 & $79.6 \pm 17.7$ \\
TransmEA & 1,463 & $0.93 \pm 0.26$ \\
Ésept, cm/s & 1,482 & $7.9 \pm 2.7$ \\
Ásept, cm/s & 1,464 & $11.8 \pm 2.8$ \\
EÁsep & 1,460 & $0.68 \pm 0.19$ \\
Élat, cm/s & 1,485 & $10.4 \pm 3.5$ \\
Álat, cm/s & 1,465 & $13.6 \pm 3.5$ \\
EÁlat & 1,465 & $0.78 \pm 0.29$ \\
Émean & 1,488 & $9.14 \pm 2.9$ \\
A_mean & 1,467 & $12.7 \pm 2.8$ \\
E/Ésept & 1,471 & $10.0 \pm 4.0$ \\
E/Élat & 1,472 & $7.8 \pm 3.5$ \\
meanÉ/Á & 1,467 & $0.73 \pm 0.21$ \\
meanE/É & 1,475 & $8.9 \pm 3.5$ \\
LAarea & 1,484 & $19.8 \pm 3.8$ \\
LASd, mm & 1,477 & $40.4 \pm 5.5$ \\
LAsdm2 & 1,477 & $20.9 \pm 2.6$ \\
LVMI & 1,477 & $88.7 \pm 21.9$ \\
LAarea/BSA & 1,452 & $10.2 \pm 1.9$ \\
\hline
\end{tabular}

LVEF, left ventricular ejection fraction; E, Doppler measurement of peak velocity of blood flow through the mitral valve in early E diastole; A, Doppler measurement of peak velocity of blood flow through the mitral valve in late diastole; TransmEA, the ratio between E and A; Ésept, peak myocardial velocity of the basal LV wall in early diastole in the septal wall; Ásept, peak myocardial velocity of the basal LV wall in late diastole in the septal wall; EÁsept,É/Á ratio septal; Élat, peak myocardial velocity of the basal $\mathrm{LV}$ wall in early diastole in the lateral wall; Álat, peak myocardial velocity of the basal LV wall in late diastole in the lateral wall; EÁlat, É/Á ratio lateral; É_mean, the mean value of peak myocardial velocity of the basal LV wall in early diastole in the lateral and septal walls; Ámean, the mean value of peak myocardial velocity of the basal LV wall in late diastole in the lateral and septal walls; E/Èsept, E/É ratio of the septal wall; E/Élat, E/É ratio of the lateral wall; meanÉ/Á, ratio of É_mean/Á_mean; meanE/É, the mean value of E/Ésept and E/Élat; LAarea, left atrium area; LASd, left atrium systolic diameter; LAsdm2, left atrial dimension/body surface area; LVMI, left ventricular mass index; LAarea/BSA, left atrium area/body surface area.

In a further analysis comparing different eGFR categories we found that compared to individuals with eGFR $>90 \mathrm{~mL} / \mathrm{min} / 1.73 \mathrm{~m}^{2}$ those with eGFR $45-60 \mathrm{~mL} / \mathrm{min} / 1.73 \mathrm{~m}^{2}$ had significantly higher E/Élat ( $p=0.015)$ and lower mean É/Á $(p=0.019)$. This difference was also seen when comparing individuals with eGFR $>90 \mathrm{~mL} / \mathrm{min} / 1.73 \mathrm{~m}^{2}$ and those with eGFR of 30-60 mL/min/1.73 $\mathrm{m}^{2}$ (Table 4). Furthermore, individuals with eGFR of $45-60 \mathrm{~mL} /$ $\mathrm{min} / 1.73 \mathrm{~m}^{2}$ had significantly higher E/Élat $(p=0.013)$ and significantly lower mean É/Á $(p=0.037)$ than individuals with eGFR $>60 \mathrm{~mL} / \mathrm{min} / 1.73 \mathrm{~m}^{2}$ (Table 5).

We also studied those with eGFR $>60 \mathrm{~mL} / \mathrm{min} / 1.73 \mathrm{~m}^{2}$ separately. The associations between eGFR as a linear variable and E/Ésept $(p=0.018)$, E/Élat $(p=0.026)$, and mean E/É $(p=0.016)$ are shown in Table 6.

\section{Associations between eGFR and Cardiac Structure}

Among the structural parameters, we found significant associations between eGFR and left atrium systolic diameter in mm (LASd; $p=0.027$ ) and LAarea/BSA ( $p=0.013$ ). In sexspecific analyses these associations were no longer significant. 
Xhakollari et al.: Echocardiographic Findings in Patients with Mild to Moderate Chronic Kidney Disease without Symptomatic Heart Failure: A Population-Based Study

Table 3. Associations between eGFR categories and different echocardiographic variables tested in a multivariable analysis adjusted for age, sex, RAAS medication, DM, hypertension, and smoking

\begin{tabular}{|c|c|c|c|c|c|c|c|}
\hline \multirow[t]{2}{*}{ Variable } & \multirow[t]{2}{*}{$n$} & \multicolumn{2}{|l|}{ All } & \multicolumn{2}{|l|}{ Women } & \multicolumn{2}{|l|}{ Men } \\
\hline & & $F$ value & $p$ value & $F$ value & $p$ value & $F$ value & $p$ value \\
\hline LVEF, \% & 1,461 & 3.429 & 0.004 & 1.119 & 0.350 & 2.798 & 0.016 \\
\hline $\mathrm{A}, \mathrm{cm} / \mathrm{s}$ & 1,427 & 3.669 & 0.003 & 0.814 & 0.540 & 4.713 & 0.000 \\
\hline E/Ésept & 1,429 & 1.872 & 0.096 & 1.293 & 0.266 & 1.748 & 1.21 \\
\hline E/Élat & 1,430 & 3.861 & 0.002 & 2.046 & 0.071 & 2.348 & 0.039 \\
\hline meanÉ/Á & 1,424 & 2.536 & 0.027 & 0.512 & 0.768 & 2.719 & 0.019 \\
\hline meanÉ/É & 1,433 & 3.081 & 0.009 & 1.563 & 0.169 & 2.183 & 0.054 \\
\hline LASd, mm & 1,435 & 2.536 & 0.027 & 1.407 & 0.221 & 3.178 & 0.007 \\
\hline LAsdm2 & 1,435 & 2.037 & 0.071 & 1.104 & 0.358 & 1.842 & 0.102 \\
\hline LAarea, $\mathrm{cm}^{2}$ & 1,409 & 2.596 & 0.024 & 1.807 & 0.110 & 1.631 & 0.149 \\
\hline LAarea/BSA & 1,409 & 2.910 & 0.013 & 1.940 & 0.087 & 1.299 & 0.262 \\
\hline
\end{tabular}

LVEF, left ventricular ejection fraction; A, Doppler measurement of peak velocity of blood flow through the mitral valve in late diastole; E/Èsept, ratio of Doppler measurement of peak velocity of blood flow through the mitral valve in early diastole and peak myocardial velocity of the basal LV wall in early diastole in the septal wall; E/Èlat, ratio of Doppler measurement of peak velocity of blood flow through the mitral valve in early diastole/peak myocardial velocity of the basal LV wall in early diastole in the lateral wall; meanÉ/Á, ratio of the mean value of peak myocardial velocity of the basal LV wall in early diastole in the lateral and septal walls/the mean value of peak myocardial velocity of the basal LV wall in late diastole in the lateral and septal walls; meanE/É, the mean value of E/Ésept and E/Élat; LAarea, left atrium area; LASd, left atrium systolic diameter; LAsdm2, left atrium dimension/body surface area; LAarea/BSA, left atrium area/body surface area.

\section{Discussion}

Our main findings from this community-based and cross-sectional cohort study demonstrate that even mild to moderate renal dysfunction was associated with echocardiographic indicators of DD in individuals without established CHF. When stratifying for sex, the associations remained significant only for men. Secondly, we also found that there was an association between eGFR as a continuous variable and diastolic function within the range of $60-115 \mathrm{~mL} / \mathrm{min} / 1.73 \mathrm{~m}^{2}$. A significant association between impairment of renal function and echocardiographic markers of cardiac structure was also seen.

The cardiorenal syndrome has great clinical implications since fatal CVD is the major cause of mortality among patients with CKD. Therapeutic interventions at early stages of CHF, even before the presence of LV hypertrophy, have shown reduced morbidity and mortality in heart failure [21].

There are numerous studies which have found an association between moderate to severe renal dysfunction and systolic and diastolic LV function. Several of these studies have been performed in subsets of patients with heart failure [22], or DM [23], for example. Also, early renal dysfunction has been studied in relation to systolic [10] and diastolic cardiac function [24].

However, community-based studies are scarce, and the results so far have not been consistent $[10,11,12]$. Differences in study populations, prevalence rates of CHF and CKD, methods of estimation of eGFR and cardiac function/structure, as well as other factors, may be responsible for these differences.

Nerpin et al. [10] demonstrated an association between systolic but not diastolic function and eGFR in two elderly populations $(n=911)$. These individuals had an LVEF $>40 \%$ and 
Table 4. Associations between eGFR groups 30-60 versus eGFR $>90 \mathrm{~mL} / \mathrm{min} / 1.73 \mathrm{~m}^{2}$ and different echocardiographic variables adjusted for age, RAAS medication, DM, hypertension, and smoking

\begin{tabular}{|c|c|c|c|c|c|c|c|c|c|}
\hline \multirow[t]{2}{*}{ Variable } & \multirow[t]{2}{*}{$n(\mathrm{~W} / \mathrm{M})$} & \multicolumn{2}{|c|}{ Mean value \pm SD } & \multicolumn{2}{|c|}{$\begin{array}{l}\text { eGFR 30-60 } \\
\text { vs. }>90 \text {, all }\end{array}$} & \multicolumn{2}{|c|}{$\begin{array}{l}\text { eGFR } 30-60 \\
\text { vs. }>90, W\end{array}$} & \multicolumn{2}{|c|}{$\begin{array}{l}\text { eGFR } 30-60 \\
\text { vs. }>90, \mathrm{M}\end{array}$} \\
\hline & & eGFR $30-60$ & eGFR >90 & $F$ value & $p$ value & $F$ value & $p$ value & $F$ value & $p$ value \\
\hline LVEEF\% & $555(189 / 366)$ & $60.2 \pm 0.8$ & $62.7 \pm 1.4$ & 7.757 & 0.006 & 0.707 & 0.402 & 7.012 & 0.008 \\
\hline E/Élat & $543(185 / 358)$ & $9.0 \pm 0.5$ & $8.05 \pm 0.8$ & 4.229 & 0.040 & 0.927 & 0.337 & 3.396 & 0.066 \\
\hline meanÉ/Á & $542(184 / 358)$ & $0.71 \pm 0.03$ & $0.80 \pm 0.04$ & 4.434 & 0.036 & 1.759 & 0.186 & 2.477 & 0.116 \\
\hline \multirow[t]{2}{*}{ Variable } & $n(\mathrm{~W} / \mathrm{M})$ & \multicolumn{2}{|c|}{ Mean value \pm SD } & \multicolumn{2}{|c|}{$\begin{array}{l}\text { eGFR } 30-45 \\
\text { vs. }>90 \text {, all }\end{array}$} & \multicolumn{2}{|c|}{$\begin{array}{l}\text { eGFR } 30-45 \\
\text { vs. }>90, \mathrm{~W}\end{array}$} & \multicolumn{2}{|c|}{$\begin{array}{l}\text { e-GFR 30-45 } \\
\text { vs. >90, M }\end{array}$} \\
\hline & & eGFR 30-45 & eGFR >90 & $F$ value & $p$ value & $F$ value & $p$ value & $F$ value & $p$ value \\
\hline LVEF\% & $256(66 / 190)$ & $59.9 \pm 1.7$ & $62.1 \pm 1.7$ & 1.897 & 0.170 & 0.018 & 0.893 & 2.264 & 0.134 \\
\hline E/Élat & $253(64 / 189)$ & $9.17 \pm 0.9$ & $8.05 \pm 0.9$ & 2.544 & 0.112 & & & & \\
\hline meanÉ/Á & $252(64 / 188)$ & $0.70 \pm 0.08$ & $0.80 \pm 0.05$ & 1.045 & 0.308 & & & & \\
\hline \multirow[t]{2}{*}{ Variable } & $n(\mathrm{~W} / \mathrm{M})$ & \multicolumn{2}{|c|}{ Mean value \pm SD } & \multicolumn{2}{|c|}{$\begin{array}{l}\text { eGFR } 45-60 \\
\text { vs. }>90 \text {, all }\end{array}$} & \multicolumn{2}{|c|}{$\begin{array}{l}\text { eGFR } 45-60 \\
\text { vs. }>90, \mathrm{~W}\end{array}$} & \multicolumn{2}{|c|}{$\begin{array}{l}\text { eGFR } 45-60 \\
\text { vs. }>90, \mathrm{M}\end{array}$} \\
\hline & & eGFR 45-60 & eGFR >90 & $F$ value & $p$ value & $F$ value & $p$ value & $F$ value & $p$ value \\
\hline LVEF\% & $461(146 / 315)$ & $60.4 \pm 0.9$ & $62.5 \pm 1.5$ & 9.144 & 0.003 & 1.101 & 0.296 & 7.652 & 0.006 \\
\hline E/Élat & $451(144 / 307)$ & $8.8 \pm 0.6$ & $8.05 \pm 0.8$ & 5.957 & 0.015 & 1.165 & 0.282 & 4.796 & 0.029 \\
\hline meanÉ/Á & $451(143 / 308)$ & $0.72 \pm 0.3$ & $0.8 \pm 0.4$ & 5.510 & 0.019 & 2.418 & 0.122 & 2.851 & 0.092 \\
\hline
\end{tabular}

W, women; M, men; LVEF, ejection fraction; E/Élat, ratio of Doppler measurement of peak velocity of blood flow through the mitral valve in early diastole/peak myocardial velocity of the basal LV wall in early diastole in the lateral wall; meanÉ/Á, ratio of the mean value of peak myocardial velocity of the basal LV wall in early diastole in the lateral and septal walls/the mean value of peak myocardial velocity of the basal $\mathrm{LV}$ wall in late diastole in the lateral and septal walls.

eGFR was estimated using CysC. The authors also separately studied individuals with eGFR above $60 \mathrm{~mL} / \mathrm{min} / 1.73 \mathrm{~m}^{2}$ and found a continuous positive relationship between eGFR and LVEF. Similar findings confirming better heart function were found in our study with a positive association between eGFR $>60 \mathrm{~mL} / \mathrm{min} / 1.73 \mathrm{~m}^{2}$ as a linear variable, and several echocardiographic indices, including measurements of diastolic function.

In the Multi-Ethnic Study of Atherosclerosis (MESA), Agarwal et al. [11] included 4,970 individuals aged 44-80 years, representing a younger population than in our study. They studied the correlation between CysC quartiles and LV structure and function measured by magnetic resonance imaging. This showed a continuous relationship between higher quartiles of CysC and lower LV end-diastolic and end-systolic volumes and concentricity, but could not demonstrate any significant association between mild to moderate reduction in kidney function estimated using CysC and LVEF.

Recently, Jain et al. [12] investigated 2,056 individuals with preserved LVEF from the Rochester Epidemiology Project and demonstrated an association between worsening eGFR and the degree of DD. In their study, eGFR was estimated with the MDRD formula derived from serum creatinine levels, and ranged from below 30 to above $90 \mathrm{~mL} / \mathrm{min} / 1.73 \mathrm{~m}^{2}$. Their results are in agreement with our findings. To our knowledge, the studies by Jain et al. [12] together with ours are the only community-based studies of diastolic function in early renal impairment. Jain et al. [12] also performed a prospective analysis and found that those with 
Table 5. Associations between eGFR groups versus eGFR $>60 \mathrm{~mL} / \mathrm{min} / 1.73 \mathrm{~m}^{2}$ and different echocardiographic variables adjusted for age, RAAS medication, DM, hypertension, and smoking

\begin{tabular}{|c|c|c|c|c|c|c|c|c|c|}
\hline \multirow[t]{2}{*}{ Variable } & \multirow[t]{2}{*}{$n(\mathrm{~W} / \mathrm{M})$} & \multicolumn{2}{|c|}{ Mean value \pm SD } & \multicolumn{2}{|c|}{$\begin{array}{l}\text { eGFR } 30-60 \\
\text { vs. }>60 \text {, all }\end{array}$} & \multicolumn{2}{|c|}{$\begin{array}{l}\text { eGFR } 30-60 \\
\text { vs. }>60, \mathrm{~W}\end{array}$} & \multicolumn{2}{|c|}{$\begin{array}{l}\text { eGFR } 30-60 \\
\text { vs. }>60, \mathrm{M}\end{array}$} \\
\hline & & eGFR 30-60 & eGFR $>60$ & $F$ value & $p$ value & $F$ value & $p$ value & $F$ value & $p$ value \\
\hline LVEEF\% & $1,453(428 / 1,025)$ & $60.2 \pm 0.7$ & $61.3 \pm 0.6$ & 4.956 & 0.026 & 1.482 & 0.224 & 4.009 & 0.046 \\
\hline E/Élat & $1,422(419 / 1,003)$ & $8.9 \pm 0.4$ & $8.1 \pm 0.3$ & 4.224 & 0.040 & 1.705 & 0.192 & 2.622 & 0.106 \\
\hline meanÉ/Á & 1,417 (419/998) & $0.71 \pm 0.02$ & $0.79 \pm 0.02$ & 3.235 & 0.072 & 0.679 & 0.410 & 2.655 & 0.104 \\
\hline \multirow[t]{2}{*}{ Variable } & $n(\mathrm{~W} / \mathrm{M})$ & \multicolumn{2}{|c|}{ Mean value \pm SD } & \multicolumn{2}{|c|}{$\begin{array}{l}\text { eGFR } 30-45 \\
\text { vs. }>60 \text {, all }\end{array}$} & \multicolumn{2}{|c|}{$\begin{array}{l}\text { eGFR } 30-45 \\
\text { vs. }>60, \mathrm{~W}\end{array}$} & \multicolumn{2}{|c|}{$\begin{array}{l}\text { eGFR } 30-45 \\
\text { vs. }>60, \mathrm{M}\end{array}$} \\
\hline & & eGFR 30-45 & eGFR >60 & $F$ value & $p$ value & $F$ value & $p$ value & $F$ value & $p$ value \\
\hline LVEF\% & $1,154(305 / 849)$ & $60 \pm 1.3$ & $61.2 \pm 0.6$ & 0.310 & 0.577 & & & & \\
\hline E/Élat & $1,132(298 / 834)$ & $9.17 \pm 0.7$ & $8.11 \pm 0.3$ & 0.122 & 0.727 & & & & \\
\hline meanÉ/Á & $1,127(299 / 828)$ & $0.7 \pm 0.04$ & $0.79 \pm 0.02$ & 0.085 & 0.771 & & & & \\
\hline \multirow[t]{2}{*}{ Variable } & $n(\mathrm{~W} / \mathrm{M})$ & \multicolumn{2}{|c|}{ Mean value \pm SD } & \multicolumn{2}{|c|}{$\begin{array}{l}\text { e-GFR } 45-60 \\
\text { vs. }>60 \text {, all }\end{array}$} & \multicolumn{2}{|c|}{$\begin{array}{l}\text { eGFR } 45-60 \\
\text { vs. }>60, \mathrm{~W}\end{array}$} & \multicolumn{2}{|c|}{$\begin{array}{l}\text { eGFR } 45-60 \\
\text { vs. }>60, \mathrm{M}\end{array}$} \\
\hline & & eGFR 45-60 & $\mathrm{eGFR}>60$ & $F$ value & $p$ value & $F$ value & $p$ value & $F$ value & $p$ value \\
\hline LVEF\% & $1,359(385 / 974)$ & $60.3 \pm 0.8$ & $61.3 \pm 0.6$ & 5.954 & 0.015 & 1.867 & 0.173 & 4.666 & 0.031 \\
\hline E/Élat & $1,330(378 / 952)$ & $8.7 \pm 0.4$ & $8.2 \pm 0.3$ & 6.230 & 0.013 & 1.859 & 0.174 & 4.466 & 0.035 \\
\hline meanÉ/Á & $1,326(378 / 948)$ & $0.7 \pm 0.03$ & $0.74 \pm 0.02$ & 4.378 & 0.037 & 0.631 & 0.427 & 4.242 & 0.040 \\
\hline
\end{tabular}

W, women; M, men; LVEF, ejection fraction; E/Élat, ratio of Doppler measurement of peak velocity of blood flow through the mitral valve in early diastole/peak myocardial velocity of the basal LV wall in early diastole in the lateral wall; meanÉ/Á, ratio of the mean value of peak myocardial velocity of the basal $\mathrm{LV}$ wall in early diastole in the lateral and septal walls/the mean value of peak myocardial velocity of the basal $\mathrm{LV}$ wall in late diastole in the lateral and septal walls.

DD had a greater mortality and morbidity (heart failure and hospitalizations) after 6 years of follow-up. DD was estimated with pulsed wave Doppler examination of mitral inflow both before and during a Valsalva maneuver and Doppler tissue imaging of the mitral annulus. Diastolic function was classified as follows: grade 1 or impaired relaxation, grade 2 or pseudonormal pattern, and grade $3+$ or restrictive pattern. DD was defined as having grade 2 or grade $3+$.

One disadvantage may be that Jain et al. [12] measured serum creatinine levels within 3 months in relation to the echocardiographic examination [12]. The authors compared echocardiographic indices of individuals with CKD stages 1,2, and 3 versus CKD stage 4 at baseline. However, in our study the association between renal function and diastolic function was also estimated from comparisons between echocardiographic indices of individuals with CKD stage 3 a versus 1 and CKD stage 3 a versus 2 . Thus, we could demonstrate this association also at very early CKD stages.

The association between eGFR and diastolic function in our study was not seen in women. This could partly be due to the low number of women in our cohort: 449 (29.9\%) of the 1,504 participants. Other reasons may be due to significant differences regarding the use of RAAS blockers, and occurrence of DM or smoking between men and women. It has been shown that women run a lower risk of CKD progression and death compared to men. One of the explanations for this can be the protective effect of endogenous estrogens and/or the deleterious effects of testosterone. 
Table 6. Associations between linear eGFR $>60 \mathrm{~mL} / \mathrm{min} / 1.73 \mathrm{~m}^{2}$ and different echocardiographic variables adjusted for age, sex, RAAS medication, DM, hypertension, and smoking

\begin{tabular}{|c|c|c|c|c|c|c|c|}
\hline \multirow[t]{2}{*}{ Variable } & \multirow[t]{2}{*}{$n$} & \multicolumn{2}{|l|}{ All } & \multicolumn{2}{|l|}{ Women } & \multicolumn{2}{|l|}{ Men } \\
\hline & & $F$ value & $p$ value & $F$ value & $p$ value & $F$ value & $p$ value \\
\hline LVEF, \% & 1,060 & 13.228 & 0.000 & 0.866 & 0.353 & 13.386 & 0.000 \\
\hline $\mathrm{A}, \mathrm{cm} / \mathrm{s}$ & 1,040 & 3.409 & 0.065 & & & & \\
\hline E/Ésep & 1,039 & 5.584 & 0.018 & 1.568 & 0.212 & 3.757 & 0.053 \\
\hline E/Élat & 1,040 & 4.947 & 0.026 & 0.525 & 0.469 & 4.538 & 0.033 \\
\hline meanÉ/Á & 1,036 & 0.447 & 0.504 & & & & \\
\hline meanE/É & 1,052 & 5.788 & 0.016 & 1.232 & 0.268 & 4.354 & 0.037 \\
\hline LASd, mm & 1,034 & 5.280 & 0.022 & 0.205 & 0.651 & 7.352 & 0.007 \\
\hline LAsdm2 & 1,034 & 0.570 & 0.450 & & & & \\
\hline LAarea, $\mathrm{cm}^{2}$ & 1,020 & 0.201 & 0.654 & & & & \\
\hline LAarea/BSA & 1,020 & 3.163 & 0.076 & & & & \\
\hline
\end{tabular}

LVEF, left ventricular ejection fraction; A, Doppler measurement of peak velocity of blood flow through the mitral valve in late diastole; E/Ésept, ratio of Doppler measurement of peak velocity of blood flow through the mitral valve in early diastole and peak myocardial velocity of the basal LV wall in early diastole in the septal wall; E/Élat, ratio of Doppler measurement of peak velocity of blood flow through the mitral valve in early diastole/peak myocardial velocity of the basal LV wall in early diastole in the lateral wall; meanÉ/Á, ratio of the mean value of peak myocardial velocity of the basal LV wall in early diastole in the lateral and septal walls/the mean value of peak myocardial velocity of the basal LV wall in late diastole in the lateral and septal walls; meanE/É, the mean value of E/Ésept and E/Élat; LASd, left atrium systolic diameter; LAsdm2, left atrium dimension/body surface area; LAarea, left atrium area; LAarea/BSA, left atrium area/body surface area.

Other studies have analyzed diastolic function in different patient groups. In a study of 103 patients with CKD 2-5 without heart failure, Asp et al. [25] showed that mild to moderate renal dysfunction (CKD 2-3) was associated with diastolic function. Most previous studies used echocardiography without TDI, but Asp et al. [25] used echocardiography with and without TDI. They could only show this association with the TDI measurements.

The results of our and previous studies showing that even mild renal dysfunction is associated with diastolic function could be due to different mechanisms [23]. One possible explanation may be an activation of the RAAS over a long period of time. RAAS activation leads to a more direct action on the myocardium via cardiac remodeling and myocardial fibrosis [3]. Other explanations may be derived from the pro-inflammatory state seen in CKD [26] and endothelial dysfunction [27], which can both lead to cardiomyocyte stiffening, hypertrophy, and interstitial fibrosis.

Another aspect to be considered is the inclusion criteria of our study that was randomly selected from groups defined by glucose metabolism, resulting in 30\% of the participants having DM. However, in the Acute Decompensated Heart Failure National Registry (ADHERE) study, $91 \%$ of patients with heart failure with preserved ejection fraction had a diagnosis of hypertension (44-51\%), coronary artery disease (67-73\%), or diabetes (26-31\%) [4]. Also, adjusting for diabetes did not attenuate the strength of the correlations found in our study.

\section{Strengths}

This study is based on a large community-based cohort with a high attendance rate. The representativeness was demonstrated by rather normal cardiac and renal function in this cohort. The exclusion of heart failure was based on several criteria, including hospital records, 
patient questionnaires, and echocardiographic findings. eGFR was based on CysC, which is proposed to be a more sensitive marker for renal function than creatinine, especially among the elderly population $[7,8]$. Another strength was that CysC was analyzed on the same day as echocardiography was performed.

\section{Limitations}

The cross-sectional study design limits causal analysis. Lack of urinary albumin limits the classification of CKD above eGFR $60 \mathrm{~mL} / \mathrm{min} / 1.73 \mathrm{~m}^{2}$. The KDIGO CKD classification further requires two measurements of the GFR marker with a 3-month interval. The availability of both serum creatinine and CysC would make the GFR estimation even stronger. The external validity of our findings may be limited because the prevalence of DM and hypertension was higher than in the general population, which was due to the fact that the database was initially used to evaluate myocardial structure and function by echocardiography in relation to glucometabolic status in elderly subjects.

\section{Conclusion}

A significant association between measures of early impairment of renal function and both diastolic function and echocardiographic markers of cardiac structure was observed in this large community-based cohort. This supports our hypothesis that interaction between the heart and kidney exists even in the early stages of renal impairment. Further studies are needed to assess these findings in longitudinal study settings.

\section{Acknowledgments}

We are thankful to statistician Mats Pihlsgård for statistical assistance. We also acknowledge the Swedish Kidney Foundation, Fulbright Commission, Stiftelsen för Njursjuka, Skåne University Hospital Research Fund, and the Research and Development Council of Region Skåne, Sweden, the Medical Faculty of Lund University (ALFSKANE-432021) (ALFSKANE-436111), the Research Funds of Skane University Hospital, the Crafoord Foundation, the Ernhold Lundstroms Research Foundation, the Hulda and Conrad Mossfelt Foundation, the Southwest Skanes Diabetes Foundation, the Kockska Foundation, the Swedish Heart and Lung Foundation, and Wallenberg Center for Molecular Medicine Lund University. Dr. Holzmann holds research positions funded by the Swedish Heart-Lung Foundation (grant No. 20170804), and by the regional agreement on medical training and clinical research between Stockholm County Council and Karolinska Institutet (grant No. 20170686).

\section{Statement of Ethics}

All subjects provided written informed consent to participate. The study protocol was approved by the regional ethics committee at Lund University, Sweden (LU 244-02). The study adheres to the Declaration of Helsinki.

\section{Disclosure Statement}

Dr. Holzmann received consultancy honoraria from Idorsia, Actelion, and Pfizer. All other authors have nothing to declare. 


\section{Author Contributions}

All authors contributed to the conception or design, or analysis and interpretation of data, or both. L.X., M.L., M.M., M.J.H., and A.C. drafted the report, and all authors revised it. All of the authors provided intellectual content or critical contributions to the work described, and approved the final version to be published.

\section{References}

1 Foley RN, Parfrey PS, Harnett JD, Kent GM, Martin CJ, Murray DC, et al. Clinical and echocardiographic disease in patients starting end-stage renal disease therapy. Kidney Int. 1995 Jan;47(1):186-92.

2 Ronco C, McCullough P, Anker SD, Anand I, Aspromonte N, Bagshaw SM, et al.; Acute Dialysis Quality Initiative (ADQI) consensus group. Cardio-renal syndromes: report from the consensus conference of the acute dialysis quality initiative. Eur Heart J. 2010 Mar;31(6):703-11.

3 Sun Y. The renin-angiotensin-aldosterone system and vascular remodeling. Congest Heart Fail. 2002 Jan-Feb; 8(1):11-6.

4 Ahmed A, Rich MW, Sanders PW, Perry GJ, Bakris GL, Zile MR, et al. Chronic kidney disease associated mortality in diastolic versus systolic heart failure: a propensity matched study. Am J Cardiol. 2007 Feb;99(3):393-8.

5 McAlister FA, Ezekowitz J, Tonelli M, Armstrong PW. Renal insufficiency and heart failure: prognostic and therapeutic implications from a prospective cohort study. Circulation. 2004 Mar;109(8):1004-9.

6 Ritz E, McClellan WM. Overview: increased cardiovascular risk in patients with minor renal dysfunction: an emerging issue with far-reaching consequences. J Am Soc Nephrol. 2004 Mar;15(3):513-6.

7 Kyhse-Andersen J, Schmidt C, Nordin G, Andersson B, Nilsson-Ehle P, Lindström V, et al. Serum cystatin C, determined by a rapid, automated particle-enhanced turbidimetric method, is a better marker than serum creatinine for glomerular filtration rate. Clin Chem. 1994 Oct;40(10):1921-6.

8 Sarnak MJ, Katz R, Stehman-Breen CO, Fried LF, Jenny NS, Psaty BM, et al.; Cardiovascular Health Study. Cystatin C concentration as a risk factor for heart failure in older adults. Ann Intern Med. 2005 Apr;142(7): 497-505.

9 Sharma R, Chemla E, Tome M, Mehta RL, Gregson H, Brecker SJ, et al. Echocardiography-based score to predict outcome after renal transplantation. Heart. 2007 Apr;93(4):464-9.

10 Nerpin E, Ingelsson E, Risérus U, Sundström J, Andren B, Jobs E, et al. The association between glomerular filtration rate and left ventricular function in two independent community-based cohorts of elderly. Nephrol Dial Transplant. 2014 Nov;29(11):2069-74.

11 Agarwal S, Thohan V, Shlipak MG, Lima J, Bluemke DA, Siscovick D, et al. Association between cystatin C and MRI measures of left ventricular structure and function: multi-ethnic study of atherosclerosis. Int J Nephrol. 2011;2011:153868.

12 Jain A, Scott C, Chen HH. The renal-cardiac connection in subjects with preserved ejection fraction: a population based study. ESC Heart Fail. 2017 Aug;4(3):266-73.

13 Berglund G, Eriksson KF, Israelsson B, Kjellström T, Lindgärde F, Mattiasson I, et al. Cardiovascular risk groups and mortality in an urban swedish male population: the Malmö Preventive Project. J Intern Med. 1996 Jun; 239(6):489-97.

14 Berglund G, Nilsson P, Eriksson KF, Nilsson JÅ, Hedblad B, Kristenson H, et al. Long-term outcome of the Malmö preventive project: mortality and cardiovascular morbidity. J Intern Med. 2000 Jan;247(1):19-29.

15 Leosdottir M, Willenheimer R, Plehn J, Borgquist R, Gudmundsson P, Harris TB, et al. Myocardial structure and function by echocardiography in relation to glucometabolic status in elderly subjects from 2 population-based cohorts: a cross-sectional study. Am Heart J. 2010 Mar;159(3):414-420.e4.

16 Leosdottir M, Willenheimer R, Persson M, Nilsson PM. The association between glucometabolic disturbances, traditional cardiovascular risk factors and self-rated health by age and gender: a cross-sectional analysis within the Malmö Preventive Project. Cardiovasc Diabetol. 2011 Dec;10(1):118.

17 Hunt SA, Abraham WT, Chin MH, Feldman AM, Francis GS, Ganiats TG, et al.; American College of Cardiology; American Heart Association Task Force on Practice Guidelines; American College of Chest Physicians; International Society for Heart and Lung Transplantation; Heart Rhythm Society. ACC/AHA 2005 Guideline Update for the Diagnosis and Management of Chronic Heart Failure in the Adult: a report of the American College of Cardiology/American Heart Association Task Force on Practice Guidelines (Writing Committee to Update the 2001 Guidelines for the Evaluation and Management of Heart Failure): developed in collaboration with the American College of Chest Physicians and the International Society for Heart and Lung Transplantation: endorsed by the Heart Rhythm Society. Circulation. 2005 Sep;112(12):e154-235.

18 Norlund L, Fex G, Lanke J, Von Schenck H, Nilsson JE, Leksell H, et al. Reference intervals for the glomerular filtration rate and cell-proliferation markers: serum cystatin C and serum beta 2-microglobulin/cystatin C-ratio. Scand J Clin Lab Invest. 1997 Oct;57(6):463-70.

19 Inker LA, Schmid CH, Tighiouart H, Eckfeldt JH, Feldman HI, Greene T, et al.; CKD-EPI Investigators. Estimating glomerular filtration rate from serum creatinine and cystatin C. N Engl J Med. 2012 Jul;367(1):20-9. 
20 Kidney Disease: Improving Global Outcomes (KDIGO) CKD Work Group. KDIGO 2012 clinical practice guideline for the evaluation and management of chronic kidney disease. Kidney Int. 2013;3(suppl):5-150.

21 Yusuf S, Pitt B, Davis CE, Hood WB Jr, Cohn JN; SOLVD Investigators. Effect of enalapril on mortality and the development of heart failure in asymptomatic patients with reduced left ventricular ejection fractions. $\mathrm{N}$ Engl J Med. 1992 Sep;327(10):685-91.

22 Khan NA, Ma I, Thompson CR, Humphries K, Salem DN, Sarnak MJ, et al. Kidney function and mortality among patients with left ventricular systolic dysfunction. J Am Soc Nephrol. 2006 Jan;17(1):244-53.

23 Chen SC, Chang JM, Liu WC, Tsai YC, Tsai JC, Su HM, et al. Stepwise increases in left ventricular mass index and decreases in left ventricular ejection fraction correspond with the stages of chronic kidney disease in diabetes patients. Exp Diabetes Res. 2012;2012:789325.

24 Cai QZ, Lu XZ, Lu Y, Wang AYM. Longitudinal changes of cardiac structure and function in CKD (CASCADE Study). J Am Soc Nephrol. 2014;25:1599-608.

25 Asp AM, Wallquist C, Rickenlund A, Hylander B, Jacobson SH, Caidahl K, et al. Cardiac remodelling and functional alterations in mild-to-moderate renal dysfunction: comparison with healthy subjects. Clin Physiol Funct Imaging. 2015 May;35(3):223-30.

26 Paulus WJ, Tschöpe C. A novel paradigm for heart failure with preserved ejection fraction: comorbidities drive myocardial dysfunction and remodeling through coronary microvascular endothelial inflammation. J Am Coll Cardiol. 2013 Jul;62(4):263-71.

27 Ter Maaten JM, Damman K, Verhaar MC, Paulus WJ, Duncker DJ, Cheng C, et al. Connecting heart failure with preserved ejection fraction and renal dysfunction: the role of endothelial dysfunction and inflammation. Eur J Heart Fail. 2016 Jun;18(6):588-98. 